\title{
Race, Rural Residence, and Control of Diabetes and Hypertension
}

\author{
Arch G. Mainous III, PbD \\ Dana E. King, MD \\ David R. Garr, MD \\ William S. Pearson, MHA
}

Department of Family Medicine, Medical University of South Carolina, Charleston, SC

\begin{abstract}
PURPOSE African Americans are at increased risk for diabetes mellitus and hypertension, and rural residents have historically had decreased access to care. It is unclear whether living in a rural area and being African American confers added risks for diagnosis and control of diabetes and hypertension. The purpose of this study was to examine the prevalence of diagnosed diabetes and hypertension, as well as control of both conditions, among rural and urban African Americans and whites.
\end{abstract}

METHODS We conducted an analysis of the Third National Health and Nutrition Examination Survey (1988-1994). Non-Hispanic African Americans and non-Hispanic white adults 20 years and older were classified according to rural or urban residence $(n=11,755)$. Investigated outcomes were previously diagnosed diabetes mellitus and hypertension and control of diabetes and hypertension.

RESULTS The prevalence of diagnosed diabetes was $4.5 \%$ for urban whites, $6.5 \%$ for rural whites, 6.0\% for urban African Americans, and 9.5\% for rural African Americans. Among patients with diagnosed diabetes, 33\% of rural whites, 43\% of urban whites, $45 \%$ of urban African American, and $61 \%$ of rural African Americans had glycosylated hemoglobin $\left(\mathrm{HbA}_{1 \mathrm{c}}\right)$ levels of $8 \%$ or higher $(P<.01)$. Among patients with diagnosed hypertension, $11 \%$ of rural whites, $13 \%$ of urban whites, $20 \%$ of urban African Americans, and 23\% of rural African Americans had diastolic blood pressure greater than $90 \mathrm{mmHg}(P<.01)$. In regression models controlling for relevant variables, including body mass index, health status, access to care, education, income, and insurance, compared with rural African Americans, rural and urban whites were significantly more likely to have better glycemic control and diastolic blood pressure control. Urban African Americans also had better diabetes control than rural African Americans.

CONCLUSIONS In this nationally representative sample, rural African Americans are at increased risk for a lack of control of diabetes and hypertension.

Ann Fam Med 2004;2:563-568. DOI: 10.1370/afm.119

\section{INTRODUCTION}

$\mathrm{D}$ iabetes mellitus and hypertension are common and potentially disabling chronic diseases, affecting more than 16 million and 50 million persons, respectively, in the United States. ${ }^{1-3}$ Persons with diabetes are at increased risk for a number of serious complications, including retinopathy, renal disease, and heart disease. ${ }^{4-6}$ Persons with hypertension are at increased risk for a number of serious complications, including stroke and congestive heart failure. ${ }^{7}$ Compared with whites, African Americans have higher rates of hypertension and diabetes and have a disproportionately higher rate of complications. ${ }^{1,8}$

Rural and minority populations have historically had problems accessing care and are particularly vulnerable to the consequences of lower access to care ${ }^{9-11}$ Limited access to health care services results in fewer medical visits, underdiagnosis, lower rates of recommended monitoring tests for diabetes, and less than optimal health outcomes. ${ }^{12-16}$ Reducing 
disparities in access to care can lead to improved outcomes indistinguishable from those for fully insured persons with full access to care. ${ }^{17,18}$

Although the data suggest that persons living in rural areas and African Americans are more likely to have diabetes or hypertension, it is unclear whether both being African American and living in a rural area puts persons at even greater risk for having these diseases than either factor alone. Moreover, little information has been available regarding inadequate control of diabetes and hypertension among rural African Americans. Thus, the purpose of this study was to examine, in a nationally representative sample of US adults, the prevalence of diagnosed diabetes and hypertension, as well as control of both conditions, among urban whites, rural whites, urban African Americans, and rural African Americans.

\section{METHODS}

The study is an analysis of the National Health and Nutrition Examination Survey (NHANES) III, 1988 to 1994. NHANES III collected multistage, stratified, clustered samples from the US civilian, noninstitutionalized population. Detailed information on the plan and operation of the NHANES III has been previously published. ${ }^{19}$

Three of the 5 NHANES data files were selected for analysis: the household adult data file, examination data file, and laboratory data file. We excluded any person who did not participate in all 3 parts of the survey. Adults are defined by the National Center for Health Statistics (NCHS) and this study as any noninstitutionalized civilian 20 years of age or older.

The analysis of the NHANES III was modified to investigate rural-urban issues. Working with the NCHS Research Data Center, we were able to merge participant residence in a metropolitan statistical area, data not available in the public use data sets, with the other public use NHANES III data. All findings reported in this study were checked at the NCHS Research Data Center by the confidentiality officer before being released to the investigators.

The Institutional Review Board of the Medical University of South Carolina reviewed the research plan and certified it as exempt.

\section{Variables}

\section{Independent Variables}

The participant's race and ethnicity were self-reported. We used the NHANES III racial and ethnic categories of non-Hispanic white and non-Hispanic African American.

Residence in a metropolitan statistical area was categorized as urban, whereas residence outside a met- ropolitan statistical area was considered rural for the purposes of this study.

\section{Dependent Variables}

A diagnosis of diabetes was assessed by an item asking whether a doctor has ever told the participant that he or she has diabetes. Persons with gestational diabetes were excluded from this categorization.

Among patients with diagnosed diabetes, we assessed glycemic control and the presence of diabetic retinopathy. For glycemic control we classified persons with a glycosylated hemoglobin $\left(\mathrm{HbA}_{1 \mathrm{c}}\right)$ level of $8 \%$ or higher as having poor control, because this level corresponds to the American Diabetes Association action point for glycemic control. ${ }^{20,21}$

A diagnosis of hypertension was assessed by an item asking whether the participant had ever been told on at least 2 occasions by a doctor that he or she has high blood pressure or hypertension.

Among patients with diagnosed hypertension, we assessed systolic and diastolic blood pressure for control. We examined systolic and diastolic blood pressure separately. Control was defined as a systolic blood pressure of $140 \mathrm{mmHg}$ or less or a diastolic pressure of $90 \mathrm{mmHg}$ or less. As with diabetes, we also assessed whether patients with diagnosed hypertension were using physician-prescribed medications for blood pressure control.

\section{Covariates and Confounding Variables}

We measured several variables that might affect the likelihood of recognition and control of diabetes and hypertension. These variables included a single 5 -point item (excellent to poor) rating of self-perceived health status. We categorized the population according to data from the physical examination and computed the body mass index (BMI) $\left(\mathrm{kg} / \mathrm{m}^{2}\right)$. We also assessed the sex and age of the participant.

Several social variables were also measured as potential covariates. Usual source of care was measured as whether the participant reported a usual place for health care and, if so, a usual doctor. Furthermore, outpatient visits and hospital stays in the past 12 months were assessed, as well as how long it had been since the last doctor visit. Each participant's total annual household income, attained education, and presence of health insurance were assessed. We categorized health insurance as publicly funded (eg, Medicaid, Medicare, CHAMPUS), privately funded, or no insurance.

\section{Analysis}

The population under study was restricted to adult nonHispanic African Americans and non-Hispanic whites $(\mathrm{n}=11,755)$ in an effort to have sufficient raw numbers 
to make valid population estimates for the rural and urban groups. The total numbers of persons used in the analysis for each of the 4 groups were 4,978 urban whites, 2,119 rural whites, 3,729 urban African Americans, and 929 rural African Americans. Because minorities were oversampled and a complex sampling design was used in the NHANES III, sampling weights provided by the National Center for Health Statistics were used to compute population estimates based on weighted parameter estimates and standard errors. The SUDAAN statistical package (RTI International, Research Triangle Park, NC) was used to provide national estimates representative of the adult civilian, noninstitutionalized population.

Chi-square analyses were used to compare the categorical data. Two sets of logistic regression models were computed to determine the independent relationship of the residence/race variable with control of disease. The regressions focused on the outcomes of elevated $\mathrm{HbA}_{1 \mathrm{c}}$ levels among participants with diagnosed diabetes and of elevated systolic and diastolic blood pressure among participants with diagnosed hypertension. The first models focused on demographic and health-related variables-residence/race, age, sex, BMI, and perceived health status. The second set of models added to those variables the social and access variables of income, insurance status, education, usual source of care, and number of times seeing the doctor in the past year.

Because models with dummy variables, such as the residence/race variable used here, compare the odds of a category with the reference category (everyone with rural African Americans), comparisons between other categories cannot be made. Consequently, we also computed the models with urban whites as the reference category so that a greater understanding of the relationship between the groups could be made.

\section{RESULTS}

The demographic characteristics of the adult US population meeting our inclusion criteria are featured in Table 1. Rural African Americans have worse selfreported health status than their counterparts, are more likely to be overweight $(\mathrm{BMI}>25)$, and are the least likely to have finished high school.

The findings related to access to care for the population are also featured in Table 1 and indicate that rural adults have a higher likelihood than urban adults of having a usual provider. Urban African Americans are the least likely to have a usual provider. Urban whites have the highest proportion with health insurance and the highest proportion with annual household incomes greater than $\$ 20,000$.

Rural African Americans are more likely than the other groups to have previously diagnosed hypertension or diabetes (Table 2), with the lowest prevalence among urban whites. Table 2 shows that for glycosylated hemoglobin, rural African Americans are the least likely to be in control. Among patients with hypertension, rural African Americans have the highest proportion of persons with elevated diastolic blood pressure, although no significant relationship was found for the residence/race categorization and systolic hypertension.

Rural African Americans are more likely than the other residence/race groups to have been recommended to take medication for their hypertension $(82.7 \%)$ and have a larger discrepancy between the proportion who were recommended to take medication and those who are currently on medication. In terms of the discrepancy between recommendation and use, rural African Americans had a 24.4\% difference, and rural whites had a $17.0 \%$ difference.

The results in Table 3 display the relationship between the residence/race categories and intermediate measures of control for patients with diabetes while adjusting for potential confounding variables. The data indicate that rural African Americans are substantially worse than the other groups in terms of glycemic control. In full-model analyses that used urban whites as the reference category, urban African Americans were not significantly different from urban whites in terms of glycemic control (odds ratio $[\mathrm{OR}]=0.94,95 \%$ confidence interval $[\mathrm{CI}], 0.58-1.53)$. Compared with both rural and urban whites, rural African Americans had a higher likelihood of elevated systolic and diastolic blood pressure. Rural and urban African Americans, however, do not differ significantly in blood pressure control. In full analyses that used urban whites as the reference category, urban African Americans had significantly worse control of both systolic $(\mathrm{OR}=1.57$, $95 \% \mathrm{CI}, 1.25-1.97)$ and diastolic blood pressure (OR $=1.71,95 \% \mathrm{CI}, 1.24-2.36)$. The addition of the access and socioeconomic factors in the full model did not eliminate the significant association between being rural and African American and having worse control of diabetes and hypertension.

\section{DISCUSSION}

The results of this study indicate that for diabetes and hypertension there is a double dose of risk for rural African Americans. This group has higher rates of diagnosed diabetes and hypertension, as well as worse glycemic control among patients with diabetes and worse diastolic blood pressure control among those with diagnosed hypertension. In adjusted and unadjusted population estimates, rural African Americans with diagnosed diabetes have significantly worse glycemic 
Table 1. Population Estimates of Demographic Characteristics and Access to Care Indicators

\begin{tabular}{|c|c|c|c|c|c|}
\hline $\begin{array}{l}\text { Characteristics } \\
\text { and Indicators }\end{array}$ & $\begin{array}{c}\text { Urban Whites } \\
\text { (n = 106,830,224) } \\
\%\end{array}$ & $\begin{array}{c}\text { Rural Whites } \\
(\mathrm{n}=28,330,66) \\
\%\end{array}$ & $\begin{array}{c}\text { Urban African } \\
\text { Americans } \\
\text { (n = 16,845,014) } \\
\%\end{array}$ & $\begin{array}{c}\text { Rural African } \\
\text { Americans } \\
\text { (n = 2,547,044) } \\
\%\end{array}$ & $\begin{array}{c}P \\
\text { Value }\end{array}$ \\
\hline Age & & & & & $<.01$ \\
\hline $20-34$ & 33.1 & 27.6 & 41.7 & 33.3 & \\
\hline $35-49$ & 31.3 & 25.2 & 31.3 & 29.2 & \\
\hline $50-64$ & 18.3 & 21.4 & 15.1 & 19.0 & \\
\hline $65+$ & 17.3 & 25.8 & 11.8 & 18.5 & \\
\hline Sex, male & 48.2 & 47.0 & 44.9 & 43.0 & \\
\hline Health status & & & & & $<.01$ \\
\hline Excellent & 22.7 & 18.6 & 17.1 & 10.1 & \\
\hline Very good & 34.7 & 30.0 & 24.1 & 17.2 & \\
\hline Good & 30.4 & 32.7 & 37.0 & 42.3 & \\
\hline Fair & 9.7 & 14.3 & 17.9 & 22.9 & \\
\hline Poor & 2.4 & 4.4 & 3.8 & 7.4 & \\
\hline Body mass index & & & & & $<.01$ \\
\hline$<18.5$ & 2.6 & 2.6 & 2.4 & 3.3 & \\
\hline $18.5-24.9$ & 44.6 & 40.0 & 36.4 & 33.9 & \\
\hline $25.0-29.9$ & 32.0 & 35.0 & 32.7 & 29.0 & \\
\hline $30.0+$ & 20.7 & 22.4 & 28.4 & 33.8 & \\
\hline $\begin{array}{l}\text { Highest year of school } \\
\text { completed }>12 y\end{array}$ & 46.8 & 28.4 & 30.5 & 14.7 & \\
\hline Health Insurance & & & & & $<.01$ \\
\hline Public & 6.1 & 8.9 & 21.1 & 27.9 & \\
\hline Private & 85.4 & 79.1 & 64.0 & 58.8 & \\
\hline None & 8.4 & 12.0 & 14.9 & 13.2 & \\
\hline Income $\geq \$ 20,000$ & 75.4 & 56.7 & 48.2 & 28.9 & \\
\hline Usual source of care, none & 20.7 & 16.0 & 24.3 & 15.9 & \\
\hline Hospital stays in last year & & & & & $<.01$ \\
\hline No visits & 88.2 & 86.50 & 84.4 & 84.5 & \\
\hline 1 visit & 8.4 & 10.2 & 11.4 & 11.4 & \\
\hline 2 or more visits & 3.4 & 3.3 & 4.2 & 4.0 & \\
\hline Physician visits in last year & & & & & .09 \\
\hline No visits & 20.3 & 22.3 & 21.8 & 22.7 & \\
\hline 1 visit & 21.6 & 19.4 & 22.9 & 21.6 & \\
\hline 2 or more visits & 58.0 & 58.3 & 55.4 & 55.7 & \\
\hline $\begin{array}{l}\text { Time since physician visit } \\
\leq 12 \mathrm{mo}\end{array}$ & 82.8 & 80.8 & 82.4 & 81.7 & \\
\hline
\end{tabular}

Table 2. Diagnosis and Control of Diabetes and Hypertension

\begin{tabular}{|c|c|c|c|c|c|}
\hline Characteristic & $\begin{array}{c}\text { Urban } \\
\text { Whites } \\
\%\end{array}$ & $\begin{array}{c}\text { Rural } \\
\text { Whites } \\
\%\end{array}$ & $\begin{array}{c}\text { Urban } \\
\text { African } \\
\text { Americans } \\
\%\end{array}$ & $\begin{array}{c}\text { Rural } \\
\text { African } \\
\text { Americans } \\
\%\end{array}$ & $\begin{array}{c}P \\
\text { Value }\end{array}$ \\
\hline Previously diagnosed diabetes & 4.5 & 6.5 & 6.0 & 9.5 & $<.01$ \\
\hline Previously diagnosed hypertension & 23.3 & 28.5 & 28.8 & 36.0 & $<.01$ \\
\hline $\begin{array}{l}\text { Previously diagnosed diabetes and } \\
\text { elevated } \mathrm{HbA}_{1 \mathrm{c}} \geq 8 \%\end{array}$ & 42.6 & 32.6 & 45.4 & 60.6 & \\
\hline $\begin{array}{l}\text { Previously diagnosed hypertension } \\
\text { and elevated systolic blood } \\
\text { pressure, }>140 \mathrm{mmHg}\end{array}$ & 38.6 & 38.1 & 41.7 & 44.1 & \\
\hline $\begin{array}{l}\text { Previously diagnosed hypertension } \\
\text { and elevated diastolic blood } \\
\text { pressure, }>90 \mathrm{mmHg}\end{array}$ & 13.5 & 11.0 & 20.2 & 23.2 & \\
\hline
\end{tabular}




\begin{tabular}{|c|c|c|}
\hline Adjusted Models* & Odds Ratio & $95 \% \mathrm{Cl}$ \\
\hline \multicolumn{3}{|l|}{ Adults with diabetes } \\
\hline \multicolumn{3}{|l|}{ Elevated $\mathrm{HbA}_{1 \mathrm{c}}{ }^{*}$} \\
\hline Urban whites & 0.49 & $0.26-0.93$ \\
\hline Rural whites & 0.32 & $0.20-0.49$ \\
\hline Urban African Americans & 0.49 & $0.32-0.76$ \\
\hline Rural African Americans & 1.00 & $1.00-1.00$ \\
\hline \multicolumn{3}{|l|}{ Elevated $\mathrm{HbA}_{1 \mathrm{c}}{ }^{\dagger}$} \\
\hline Urban whites & 0.55 & $0.31-0.95$ \\
\hline Rural whites & 0.33 & $0.21-0.52$ \\
\hline Urban African Americans & 0.53 & $0.34-0.82$ \\
\hline Rural African Americans & 1.00 & $1.00-1.00$ \\
\hline \multicolumn{3}{|l|}{ Adults with hypertension } \\
\hline \multicolumn{3}{|c|}{ Elevated systolic blood pressure* } \\
\hline Urban whites & 0.67 & $0.54-0.83$ \\
\hline Rural whites & 0.54 & $0.39-0.75$ \\
\hline Urban African Americans & 1.06 & $0.85-1.31$ \\
\hline Rural African Americans & 1.00 & $1.00-1.00$ \\
\hline \multicolumn{3}{|c|}{ Elevated systolic blood pressure ${ }^{\dagger}$} \\
\hline Urban whites & 0.68 & $0.54-0.85$ \\
\hline Rural whites & 0.53 & $0.38-0.76$ \\
\hline Urban African Americans & 1.07 & $0.85-1.34$ \\
\hline Rural African Americans & 1.00 & $1.00-1.00$ \\
\hline \multicolumn{3}{|c|}{ Elevated diastolic blood presssure* } \\
\hline Urban whites & 0.44 & $0.29-0.67$ \\
\hline Rural whites & 0.40 & $0.23-0.68$ \\
\hline Urban African Americans & 0.77 & $0.50-1.17$ \\
\hline Rural African Americans & 1.00 & $1.00-1.00$ \\
\hline \multicolumn{3}{|c|}{ Elevated diastolic blood pressure ${ }^{+}$} \\
\hline Urban whites & 0.45 & $0.30-0.68$ \\
\hline Rural whites & 0.40 & $0.24-0.68$ \\
\hline Urban African Americans & 0.77 & $0.50-1.17$ \\
\hline Rural African Americans & 1.00 & $1.00-1.00$ \\
\hline \multicolumn{3}{|c|}{$\begin{array}{l}\text { Note: elevated hemoglobin }=\mathrm{HbA}_{1 c} \geq 8.0 \% \text {; elevated systolic blood pressure }= \\
>140 \mathrm{mmHg} \text {; elevated diastolic blood pressure }=>90 \mathrm{mmHg} .\end{array}$} \\
\hline \multicolumn{3}{|c|}{$\mathrm{Cl}=$ confidence interval $; \mathrm{HbA}_{\mathrm{lc}}=$ glycosylated hemoglobin. } \\
\hline \multicolumn{3}{|c|}{$\begin{array}{l}\text { * Adjusted for age, sex, level of income, insurance coverage, and level of education. } \\
\text { † Adjusted for age, sex, level of income, insurance coverage, level of education, } \\
\text { self-reported health status, length of time with disease, body mass index, usual } \\
\text { source of care, number of times seeing physician within last year. }\end{array}$} \\
\hline
\end{tabular}

control when compared with urban African Americans and both rural and urban whites. Moreover, among persons with diagnosed hypertension, rural African Americans have worse diastolic blood pressure control when compared with both urban and rural whites. The results are consistent with findings of previous studies, suggesting increasing risk associated with minority status, but our results extend previous findings to explore the situation for residents of rural areas. The findings of this study have implications with regard not only to providing health care services but also to design- ing policies that will guide the future delivery of rural health care. Providing services that optimally meet the greater needs of the rural minority populations will be important to reduce the incidence of health problems and premature mortality in this high-risk group.

Rural African Americans far exceeded urban African Americans and rural whites in the percentage of persons who regarded their health status as fair or poor. Past data have suggested worse self-perceived health status among rural adults. ${ }^{22-24}$ It would appear that being rural and African American is associated with substantially worse perceived health.

Although the effect of access to care and insurance status on control of diabetes and hypertension was addressed in the regression models, many differences between the groups persisted even after controlling for access to care and insurance. Access to care, at least as it was measured here, does not explain why rural African Americans fare so poorly. It is possible that global measures of access to care may mask differences in access or quality of care. The finding that rural African Americans have worse diastolic blood pressure control than rural whites even after controlling for access to care may be represented in the finding that substantially more rural African Americans were recommended by a physician to take blood pressure medication, yet fewer are currently on treatment. The recent Institute of Medicine report documenting the issue of unequal treatment for racial and ethnic groups points to factors at both the patient and system level that may affect quality of care. ${ }^{25}$ These factors (eg, cultural sensitivity in assessing signs and symptoms, the ability to gather a relevant medical history, and patient adherence to treatment) may be playing a role in the diagnosis and control of chronic conditions and will not be assessed in a measure documenting simply whether the patient reports a usual source of care.

There are several limitations to this analysis that need to be mentioned. First, although the NHANES III contains substantial clinical data that arose from examinations or laboratory tests, much of the data in this study are based on self-reports. Specifically, there may be some memory or self-report bias involved in reporting on whether a doctor told the participant that he or she had a certain condition (eg, diabetes). Second, although metropolitan statistical areas are commonly used as indicators of rural or urban residence, classifying persons in this way might miss some of the nuances needed in gaining an accurate picture of rural health care needs. Classifying persons as residents of suburban, rural, and urban locales might have yielded different results. Third, because of sample size restrictions for persons in rural areas in the NHANES III, the study is limited to non-Hispanic whites and African 
Americans. Obviously, this picture of US adults is limited; however, it does provide a direction for future research. Fourth, the NHANES III provided an assessment of whether the participant had health insurance and of type of insurance, but because it did not address the adequacy of insurance coverage, underinsurance cannot be assessed. Further, access-to-care variables might not assess the difficulties and costs associated with transportation to health care facilities. Fifth, although the NHANES III had a very high response rate, some participants had missing data on different variables, which might affect the generalizability of the findings. Sixth, because the NHANES 1999-2000 survey has not yet released access-to-care information (December 2003), this data set is the most up-to-date available. Even so, the current data are 9 to 15 years old. Finally, this study is cross-sectional in nature, and thus causality cannot be established.

In summary, the national population estimates presented here show that African Americans, especially those residing in rural areas, are more likely to be less well educated, to be overweight, and to report poorer health status. Beyond these factors, they also are more likely to have poorly controlled diabetes and poorly controlled diastolic blood pressure. This study has provided important data to support the wisdom of mounting a vigorous effort to address the health problems of persons residing in rural areas, especially those who are of lower income and are African American. If greater success is to be attained, a more extensive initiative will be needed in the form of persons, programs, and resources to address the health needs that have been identified in this study.

To read or post commentaries in response to this article, see it online at http://www.annfammed.org/cgi/content/full/2/6/563.

Key words: Diabetes mellitus; rural health; African Americans; hypertension; endocrine system/metabolism; medically underserved area; minority group; circulatory system

Submitted September 18, 2003; submitted, revised, December 15, 2003; accepted January 5, 2004.

Presented at the 30th annual meeting of the North American Primary Care Research Group, New Orleans, La, November 2002.

Funding support: Supported in part by a grant from the Office of Rural Health Policy and grant 1D12HP00023-01 from the Health Resources and Services Administration.

\section{References}

1. Harris MI. Diabetes in America: epidemiology and scope of the problem. Diabetes Care. 1998;21(Suppl 3):C11-C14.

2. Rubin RJ, Altman WM, Mendelson DN. Health care expenditures for people with diabetes mellitus, 1992. J Clin Endocrinol Metab. 1994;78:809A-809F.
3. Joint National Committee on Prevention, Detection, Evaluation, and Treatment of High Blood Pressure. The sixth report of the Joint National Committee on prevention, detection, evaluation, and treatment of high blood pressure. Arch Intern Med. 1997;157:2413-2446.

4. Eastman RC, Javitt JC, Herman WH, et al. Model of complications of NIDDM. II. Analysis of the health benefits and cost-effectiveness of treating NIDDM with the goal of normoglycemia. Diabetes Care. 1997;20:735-744.

5. Wilson PW. Diabetes mellitus and coronary heart disease. Am J Kidney Dis. 1998;32(5 Suppl 3):S89-S100.

6. Sanchez-Thorin JC. The epidemiology of diabetes mellitus and diabetic retinopathy. Int Ophthalmol Clinics. 1998;38:11-18.

7. Burt VL, Whelton P, Roccella EJ, et al. Prevalence of hypertension in the US adult population. Results from the Third National Health and Nutrition Examination Survey, 1988-1991. Hypertension. $1995 ; 25: 305-313$.

8. Lackland DT, Keil JE. Epidemiology of hypertension in African Americans. Semin Nephrology. 1996;16:63-70.

9. Newacheck PW, Hughes DC, Stoddard JJ. Children's access to primary care: differences by race, income, and insurance status. Pediatrics. 1996;97:26-32.

10. Bolen JC, Rhodes L, Powell-Griner EE, Bland SD, Holtzman D. State-specific prevalence of selected health behaviors, by race and ethnicity--Behavioral Risk Factor Surveillance System, 1997. MMWR Morb Mortal Wkly Rep. 2000;49:1-60.

11. Waidmann TA, Rajan S. Race and ethnic disparities in health care access and utilization: an examination of state variation. Med Care Res Rev. 2000;57(Suppl 1):55-84.

12. Ayanian JZ, Weissman JS, Schneider EC, Ginsburg JA, Zaslavsky AM. Unmet health needs of uninsured adults in the United States. JAMA. 2000;284:2061-2069.

13. Dansky KH, Dirani R. The use of health care services by people with diabetes in rural areas. J Rural Health. 1998;14:129-137.

14. Zoorob RJ, Mainous AG III. Compliance of rural family physicians with the American Diabetes Association standards of care. J Comm Health. 1996;21:175-182.

15. Saaddine JB, Engelgau MM, Beckles GL, Gregg EW, Thompson TJ, Narayan KM. A diabetes report card for the United States: quality of care in the 1990s. Ann Intern Med. 2002;136:565-574.

16. LaVeist TA, Arthur M, Morgan A, et al. The cardiac access longitudinal study. A study of access to invasive cardiology among African American and white patients. J Am Coll Cardiol. 2003;41:1159-1166.

17. Mancini MC, Cush EM, Sweatman K, Dansby J. Coronary artery bypass surgery: are outcomes influenced by demographics or ability to pay? Ann Surg. 2001;233:617-622.

18. Williams RL, Flocke SA, Stange KC. Race and preventive services among black patients and white patients seen in primary care. Med Care. 2001;39:1260-1267

19. Plan and operation of the Third National Health and Nutrition Examination Survey, 1988-94. Series 1: programs and collection procedures. Vital Health Stat 1. 1994;32:1-407.

20. American Diabetes Association. Standards of medical care for patients with diabetes mellitus. Diabet Care. 2001;24(Suppl 1):S33-S43.

21. American Diabetes Association. Standards of medical care for patients with diabetes mellitus. Diabet Care. 1994;17:616-623.

22. Mainous AG III, Kohrs FP. A comparison of health status between rural and urban adults. J Comm Health. 1995;20:423-431.

23. Adams CE, Michel Y, DeFrates D, Corbett CF. Effect of locale on health status and direct care time of rural versus urban home health patients. J Nurs Adm. 2001;31:244-251.

24. Ramsey PW, Glenn LL. Obesity and health status in rural, urban, and suburban southern women. South Med J. 2002;95:666-671.

25. Smedley BD, Stith AY, Nelson AR, eds. Unequal Treatment: Confronting Racial and Ethnic Disparities in Health Care. Washington, DC: National Academies Press; 2002. 